\title{
Editorial: Living Along Gradients: Past, Present, Future
}

\author{
Ulrich Bathmann ${ }^{1}$, Hendrik Schubert ${ }^{2}$, Elinor Andrén ${ }^{3}$, Laura Tuomi ${ }^{4}$, \\ Teresa Radziejewska ${ }^{5}$, Karol Kulinski ${ }^{6}$ and Irina Chubarenko ${ }^{7 *}$ \\ ${ }^{1}$ Leibniz-Institute for Baltic Sea Research, Warnemünde, Germany, ${ }^{2}$ Institute of Biosciences, Ecology, University of Rostock, \\ Rostock, Germany, ${ }^{3}$ School of Natural Sciences, Technology and Environmental Studies, Södertörn University, Huddinge, \\ Sweden, ${ }^{4}$ Marine Research Unit, Finnish Meteorological Institute, Helsinki, Finland, ${ }^{5}$ Institute of Marine and Environmental \\ Sciences, University of Szczecin, Szczecin, Poland, ${ }^{6}$ Marine Biogeochemistry Laboratory, Institute of Oceanology of the \\ Polish Academy of Sciences, Sopot, Poland, ${ }^{7}$ Laboratory for Marine Physics, Shirshov Institute of Oceanology of the Russian \\ Academy of Sciences, Moscow, Russia
}

Keywords: Baltic Sea, coastal seas, hypoxia, major baltic inflow, eutrophication

\section{Editorial on the Research Topic}

\section{Living Along Gradients: Past, Present, Future}

The Baltic Sea is a geologically and evolutionarily young part of the coastal ocean that experienced, in its past, several severe environmental changes. In its present state, the Baltic Sea is characterized by both horizontal and vertical gradients of environmental conditions. As a huge estuary, it shows a west to east/south to north surface salinity gradient from 24 in Kattegat to nearly freshwater in the Bothnian Bay. The vertical salinity and oxygen gradients result in stratification which causes hypoxic and sulfidic anoxic conditions in deep basins. These gradient systems are impacted by natural and anthropogenic changes due to physico-chemical driving forces, varying over time and space. Gradient environments produce an imprint on both the structure and function of the biological systems and influence biogeochemical cycling. Besides, coastal seas in general and the Baltic Sea in particular, experience constant and direct influence from land with consequences to matter and energy cycles, biogeochemical interactions, energy fluxes, and sediment dynamics.

"Living along gradients: past, present, future" in the Baltic are today's very important aspects that rise questions like which of the effects we are detecting occur naturally, and which are driven by human activities. Deciphering past environmental changes and their causes provide keys to understand and simulate possible future scenarios, all of which should rise societal awareness and implementation of appropriate marine and coastal policies. Present-day knowledge on the dynamics of gradient systems, on the processes that affect the coastal sea environment, the results of interaction between coastal seas and society, the detection or reconstruction of past and present changes on time scales from inter-annual to millennial, and future change models are summarized here, with the idea to stimulate scientific exchange on most complex questions, addressing them from different perspectives.

\section{MONITORING AND ASSESSMENT}

Received: 09 December 2019 Accepted: 12 December 2019 Published: 10 January 2020

Citation:

Modern strategies, concepts, and tools are addressed in this paper collection, including operational oceanography, observational approaches, in-situ technologies, development of sensors and methods for their calibration, experimental studies, and numerical modeling.

Results of environmental monitoring using Argo floats are reported based on their operation in the Bothnian Sea in 2012-2017 (Haavisto et al.; Roiha et al.).

Distribution of total suspended matter across the Baltic Sea is evaluated by Kyryliuk and Kratzer who used remote sensing data of summer composites for 2009, 2010, 2011 and a 3-year summer mean (2009-2011). 
Different fractions of surfactants, collected during three research cruises in coastal and open waters of the Baltic Sea are analyzed by spectrophoto- and spectrofluorimetric methods by Drozdowska et al. Sediment cores, obtained during several cruises in the southern Baltic Sea in different seasons of 20142016 years, are used by Gogina et al. for the investigation of pore-water biogeochemistry and associated nutrient fluxes across the sediment-water interface.

An important problem of reliable calibration of $\mathrm{pH}$ instruments in the low-salinity range of brackish water is addressed by Müller et al. and Müller and Rehder.

The increase in the extent of hypoxic bottom areas in the Baltic Sea during recent decades seems to be attributed to anthropogenic forcing. In their study in the Landsort Deep, van Wirdum et al. analyse past periods of hypoxic conditions in the Baltic Sea, caused by changing climate conditions during the Holocene Thermal Maximum and Medieval Climate Anomaly.

An experimental study of biofilm formation on artificial (glass, metal, plastic) and biotic (wood, macrophytes) solid substrata deployed at a depth of $0.5 \mathrm{~m}$ in several locations in near-shore waters of the Gulf of Gdansk is presented by Grzegorczyk et al.

The skill of the state-of-the-art ocean circulation models GETM (General Estuarine Transport Model), RCO (Rossby Centre Ocean model), and MOM (Modular Ocean Model) to represent hydrographic conditions and the mean circulation of the Baltic Sea is investigated by Placke et al.

A review paper by Meier et al. assesses knowledge acquired from available literature about future scenario simulations of biogeochemical cycles in the Baltic Sea and their uncertainties, and recommends that the models' skill for the Baltic Sea region and the spread in scenario simulations (differences among the projected changes) be regularly evaluated (by comparing with observations).

Meier et al. assess the impact of the Baltic Sea Action Plan implementation on the future environmental status of the Baltic Sea and analyze the available uncoordinated multi-model ensemble simulations for the Baltic Sea region in the twentyfirst century.

\section{MAJOR BALTIC INFLOWS AND THEIR IMPACT}

An inflow of saline and oxygenated oceanic water is an oceanographic process of a key importance for the functioning of the Baltic Sea ecosystem. Major Baltic Inflows (MBI) transport large amounts of saline water into the Baltic, having a significant impact on physics, biogeochemistry, and marine life.

Mohrholz presents a reconstruction of a continuous series of barotropic inflows from the Belt Sea and the Sound for the period from 1887 till present, based on long-term data series of the sea level, river discharge, and salinity. Increased eutrophication during the last century is suggested as the main driver of the temporal and spatial spreading of suboxic and anoxic conditions in the deep layer of the Baltic Sea.
Propagation of the MBI signal from the Eastern Gotland Basin to the Gulf of Finland is dealt with by Liblik et al. based on in-situ measurements from January 2014 to March 2017, merging Estonian, Swedish, German, and Finnish oceanographic data sets. The impact of the $2014 \mathrm{MBI}$ which brought saline and oxygenated water into the basins of the central Baltic Sea, is revealed by the manganese cycling (Dellwig et al.) and by the composition and distribution of bacterioplankton communities (Bergen et al.).

\section{COASTAL WATERS AND LAGOONS}

Coastal zones link terrestrial and marine ecosystems, providing a unique environment that is under increasing anthropogenic pressure. Knowledge on the influences from the catchment, including land-ocean interactions, hydrology, and supply of various substances is important for understanding the role of coastal processes affecting the land-locked marine systems.

An interdisciplinary approach to the investigation of interactions between land and sea at shallow coasts is proposed in the Hypothesis-and-Theory paper (Jurasinski et al.). Sea-land interactions are far-reaching, occurring on either side of the interface, and can only be understood when both long-term and event-based patterns at different spatial scales are taken into account in interdisciplinary research that involves marine and terrestrial expertise.

The impact of macrofaunal communities on the coastal filter function is investigated by Thoms et al. who used faunistic, porewater, and bottom water data obtained during three cruises to the Gulf of Gdansk. Diffusive porewater nutrient fluxes are calculated and related to the total net fluxes.

Sub-marine continuation of peat deposits from a coastal peatland in the southern Baltic Sea and its Holocene development is considered by Kreuzburg et al. Based on on- and offshore sediment cores and geo-acoustic surveys, the present Heiligensee and Hütelmoor peat deposits (Northern Germany) are found to continue more than $90 \mathrm{~m}$ in front of the coastline.

Results on bioirrigation and reworking of sediments by benthic macrofauna in coastal eutrophic sediments of the Pomeranian Bay (southern Baltic Sea) are presented and discussed by Powilleit and Forster.

Sediments in eutrophic systems, suffering from long-lasting anthropogenically elevated nutrient inputs, are assumed to be an important internal nutrient source. Phosphorus content is reevaluated after 40 years by Berthold et al. in muddy and sandy sediments of the Darß-Zingst Bodden chain, a typical temperate lagoon system of the southern Baltic Sea.

Coastal marine sediments are a hotspot of organic matter degradation. Lipka et al. investigate, on a seasonal basis, the key mineralization processes in sediments (permeable sands to fine grained muds) of a shallow (15-45 m water depth) coastal area of the southern Baltic Sea.

Nutrient retention in the Swedish coastal zone is estimated by Edman et al., who found that only significantly less than a half of the nutrient input from land can be assumed to be exported from coastal waters to the open sea. 
Monthly samples in 2015-2017 from the Szczecin Lagoon (a southern Baltic coastal lagoon) allowed Wawrzyniak-Wydrowska et al. to report on changes in the abundance and biomass of two co-occurring non-indigenous dreissenids (Dreissena polymorpha and D. rostriformis bugensis), suspected of being competitors.

\section{ANTHROPOGENIC INFLUENCE}

The European Marine Strategy Framework Directive requires the development of suitable indicators for regular reporting on the environmental state and achievement of a good environmental status of EU's marine waters by 2020. In search of such an indicator, Virtasalo et al. present a study of Vuosaari and Uusikaupunki-D offshore dumping sites in Finland (northern Baltic Sea), aimed at assessing the influence of dredge spoil dumping on the seafloor geological integrity.

Properties of contaminants in the marine environment can be effectively studied under controlled laboratory conditions. Boniewicz-Szmyt and Pogorzelski describe laboratory experiments on the contaminant spreading kinetics, using crude oils surfactant-containing sea water of well-controlled thermo-elastic surface properties as an example. Fragmentation common commercial synthetic polymers (polyethylene, polypropylene, and polystyrene) in the sea swash zone is analyzed by Efimova et al. based on experiments in a rotating laboratory mixer. A time-dependent increase in the weight and number of the microplastic particles generated as well the link between them are important for field monitoring and numerical modeling of plastic contamination in the marine environment.

The volume summarizes the progress that has been achieved in broadening our knowledge on the structure and functioning of the present-day Baltic Sea ecosystems, and on its underpinnings based on recent and more distant past. Projections onto the ecosystem's future are discussed, which will depend on how well the present ecosystem is appreciated and managed. The knowledge summarized in this volume is by no means a closed chapter. The Baltic Sea continues to be intensively studied and we look forward to new insights the coming years will bring. In particular, we hope for significant insights from the novel joint Baltic Sea and North Sea Research and Innovation Programme (BANOS), expected to run from 2021 onwards, which will assume a high level of scientific, administrative and financial integration and should open new horizons for development of EU and national policies and strategies, with a particular consideration of Europe's blue growth strategy in the northern European regional seas.

\section{AUTHOR CONTRIBUTIONS}

All authors listed have made a substantial, direct and intellectual contribution to the work, and approved it for publication.

\section{ACKNOWLEDGMENTS}

We thank all authors, reviewers, and editors who have contributed to this Research Topic.

Conflict of Interest: The authors declare that the research was conducted in the absence of any commercial or financial relationships that could be construed as a potential conflict of interest.

Copyright $\odot 2020$ Bathmann, Schubert, Andrén, Tuomi, Radziejewska, Kulinski and Chubarenko. This is an open-access article distributed under the terms of the Creative Commons Attribution License (CC BY). The use, distribution or reproduction in other forums is permitted, provided the original author(s) and the copyright owner(s) are credited and that the original publication in this journal is cited, in accordance with accepted academic practice. No use, distribution or reproduction is permitted which does not comply with these terms. 